\title{
Hoja en blanco: hacia una nueva institucionalidad y régimen tributario para Chile
}

\author{
Claudio A. Agostini, ${ }^{a}$ Pablo Correa, ${ }^{b}$ Carla Maldonado ${ }^{c} y$ \\ Max Spiess ${ }^{d}$ \\ a Universidad Adolfo lbáñez, Chile \\ b Horizontal, Chile \\ c Jetti Resources, Chile \\ d Elton y Cía.Abogados, Chile
}

\begin{abstract}
RESUMEN: Regularmente, cada nuevo gobierno asume con una reforma tributaria como parte de su programa, lo cual muchas veces tensiona el desarrollo social y político del país. La repetida modificación de las reglas del juego introduce ruido en la economía, pues el vaivén legislativo genera una indeseable incerteza jurídica y económica que
\end{abstract}

Claudio A. Agostini es Doctor en Economía, Universidad de Michigan. Profesor titular de la Escuela de Gobierno, Universidad Adolfo Ibáñez, Santiago, Chile. Dirección: Diagonal Las Torres 2640, Peñalolén, Santiago, Chile, CP 8320000 . Email: claudio.agostini@uai.cl.

Pablo Correa es Magíster en Economía Aplicada, Pontificia Universidad Católica de Chile, y Magíster en Desarrollo Internacional, Universidad de Harvard. Director de Horizontal, Santiago, Chile. Dirección: Nevería 5163, Las Condes, Santiago, Chile, CP 7580090. Email: pcorreag@outlook.es.

CARLa Maldonado es abogada y Magíster en Derecho Tributario, Universidad de Chile. Directora de Operaciones en Jetti Resources, Santiago, Chile. Dirección: María Monvel 2112, La Reina, Santiago, Chile, CP 7860030. Email:carlamaldonadov@gmail.com.

Max Spiess es abogado de la Pontificia Universidad Católica de Chile y Magíster en Derecho, Universidad de Virginia. Socio de Denk Consultores en Políticas Públicas y de Elton y Cía. Abogados. Dirección: Avda. Presidente Kennedy 5454, piso 7, Vitacura, Santiago, Chile, CP 7630586. Email: max.spiess@denk.cl.

Los autores agradecen el valioso aporte de Rodrigo Winter en numerosas conversaciones, discusiones y comentarios. 
no favorece las decisiones de inversión y ahorro. A partir de un largo análisis tanto académico — considerando la teoría y la evidencia empírica existente-como aplicado - considerando las mejores prácticas internacionales-, este artículo propone repensar el sistema tributario como un todo y diseña las bases de un modelo completamente nuevo. Este nuevo sistema tributario, que busca entre otras cosas ser lo más neutral posible en términos de las distorsiones que genera un impuesto, junto a otras políticas públicas adecuadas, podría incentivar la inversión y contribuir a alcanzar condiciones de equidad y desarroIlo social. El sistema que se propone se basa en un impuesto a la renta y otro al consumo, como pilares centrales. El impuesto a la renta trata por igual el capital y el trabajo, igualando sus tasas e integrando completamente los impuestos corporativos con los impuestos personales finales. En el impuesto al consumo se propone modificar tanto la tasa como la base sobre la cual se aplica, reduciendo la primera y ampliando la segunda a actividades hoy exentas. El sistema se complementa con una profunda revisión al modelo institucional tributario, incluyendo los aspectos jurisdiccionales del mismo, donde proponemos la creación de un organismo autónomo del poder ejecutivo y con rango constitucional. Finalmente, a partir de datos y estudios académicos disponibles, estimamos la recaudación tributaria de esta propuesta. Si bien estas estimaciones no son conclusivas y requieren de mayor análisis, predicen importantes holguras o superávits respecto de la recaudación actual.

PalABRAS CLAVE: régimen tributario, institucionalidad tributaria, política tributaria, impuesto a la renta, impuesto al consumo

RECIBIDO: agosto 2020 / ACEPTADO: noviembre 2020

\section{Clean Slate:Towards a New Tax System for Chile}

ABSTRACT: In general, each new administration begins its term with a new tax reform that was part of its campaign program, which might stress the country's social and political development. The repeated changes of the rules of the game introduces uncertainty in the economy, which has a negative impact on investment and saving decisions. Based on an academic and practical analysis, which considered the theory of optimal taxation, the existing empirical evidence, and the best practices in developed countries, this work proposes a new tax system for Chile. This new tax system seeks to be as neutral as possible in terms of minimizing the distortions that taxes generate and, together with the proper public policies, it could incentive investment and contribute to reach conditions of social equity and development. The proposed system is based on an income tax and a tax on consumption as the main pillars, dismissing a wealth tax. Income tax levels the treatment between capital and work, equalizing their tax rates and fully integrating corporate taxes with personal final taxes. Regarding taxes on consumption, we propose an amendment to both the rate 
and basis over which they are applied, reducing the first, broadening the second, and covering certain activities that are currently exempted. The system is supplemented with a thorough review of the institutional tax model including its jurisdictional aspects, where we propose the creation of a fiscal authority that is autonomous from the Executive Power and with constitutional rank. Finally, based on available data and previous studies for Chile, we estimate the tax revenue arising from this proposed new tax system. Even though the estimated figures cannot be considered conclusive and require further analysis, they predict a significant surplus compared to the current tax revenue. KEYWORDS: tax system, fiscal institutions, tax policy, income tax, consumption tax

ReCEIved: August 2020 / AcCePTeD: November 2020

os países tienen el derecho, e incluso el deber, de revisar sus sistemas impositivos tantas veces como sea necesario y de ajustarlos a las nuevas realidades y necesidades. Sin embargo, esa necesidad no debe estar motivada por el logro de objetivos políticos o ideológicos de corto plazo, que pueden terminar construyendo un mal sistema tributario en el mediano y largo plazo. En general, la repetida modificación de las 'reglas del juego' introduce incertidumbre en los agentes económicos, especialmente cuando se trata de impuestos, y genera una indeseable incerteza jurídica y económica que puede tener efectos negativos, entre otras cosas, en el crecimiento económico futuro (Prescott y Parente 2000). En particular, este escenario no contribuye a crear un ambiente que facilite la toma de decisiones de trabajo, inversión, ahorro y producción y, por lo mismo, no es bueno para el desarrollo económico y social de un país.

Las naciones desarrolladas acostumbran a mirar metas en un horizonte de mediano y largo plazo, en especial en el diseño tributario, para establecer un camino y distintas etapas para llegar a esa meta. Si bien las reglas tributarias pueden cambiar producto de nuevos contextos, y es bueno que esto ocurra, lo ideal es que los objetivos y principios rectores basales se mantengan estables en el tiempo, de modo que los agentes sociales, políticos y económicos (que somos todos en distintas facetas de uno mismo) tengan certeza para poder tomar decisiones de largo plazo y con menores riesgos.

En ese contexto, en este trabajo proponemos un sistema tributario en base a cuatro principios informadores basales en los que todos 
podamos idealmente estar de acuerdo y respetar, los cuales permitan una discusión tributaria sana, basada en argumentos y evidencia, de tal forma que sea políticamente conducente a un acuerdo de largo plazo. Estos principios básicos son: recaudar lo necesario para el financiamiento del Estado; neutralidad para minimizar distorsiones; certeza y claridad jurídica que facilite la administración y el cumplimiento tributario; y una autoridad tributaria independiente.

Chile ha hecho inmensos avances sociales, políticos y económicos en los últimos 40 años, pero está todavía a medio camino del desarrollo. Logramos superar la extrema pobreza, pero el verdadero desarrollo es tarea pendiente si se trata de hacerlo equitativo, inclusivo y sustentable; al mismo tiempo que generar las herramientas y políticas públicas necesarias para enfrentar los desafíos tecnológicos que se vienen por delante.

En consecuencia, el sistema tributario debiera ser completamente funcional a la meta de alcanzar un desarrollo equitativo e inclusivo, minimizando las distorsiones que generan los impuestos en la asignación de recursos, y permitiendo financiar el Estado al menor costo posible en términos de fiscalización, administración y cumplimiento tributario. Cualquier nuevo sistema tributario debe hacerse cargo de este desafío. El sistema tributario que proponemos en este artículo, creemos que es coherente con ello en cada uno de sus elementos constructivos, a la vez de generar mayores recursos fiscales para financiar políticas públicas de inversión social y productiva que sean más directas y transparentes.

En este contexto, la propuesta que presentamos aquí busca repensar el sistema tributario como un todo, sin ninguna restricción inicial, partiendo desde una hoja en blanco, para ponerlo en línea con una economía moderna y abierta al mundo, y que al mismo tiempo sea lo más neutro posible en todas sus dimensiones. La idea no es corregir el sistema vigente ni plantear sus virtudes y sus deficiencias. Por el contrario, la pregunta central es qué sistema tributario uno quisiera tener si pudiera comenzar a diseñarlo desde cero, una hoja en blanco sin ninguna restricción. Sin duda que eso puede considerarse un ejercicio poco realista, pero la libertad teórica que produce permite fijar un norte de hacia dónde debiera moverse el sistema tributario en Chile. Proponemos, entonces, un modelo completamente nuevo que, de la mano de las políticas públicas adecuadas, podría contribuir a alcanzar condiciones de equidad y desarrollo económico y social. 
El resto del artículo se estructura de la siguiente forma. Las secciones 1 y 2 plantean los principios generales y los elementos estructurales de política tributaria sobre los que se debiera diseñar, idealmente, un sistema tributario. Las tres secciones siguientes presentan y analizan las propuestas tributarias específicas para cada impuesto: en la sección 3, el impuesto a la renta; en la sección 4, el impuesto al consumo; y en la sección 5, los impuestos especiales. La sección 6 discute por qué la propuesta de un nuevo sistema tributario descarta incorporar un impuesto al patrimonio. La sección 7 propone una nueva institucionalidad tanto para la administración como para la justicia tributaria. La sección 8 presenta una estimación de la recaudación potencial del nuevo sistema tributario propuesto y, finalmente, la sección 9 concluye.

\section{Principios fundamentales}

Para abrir cualquier discusión amplia sobre un sistema tributario, es primordial explicitar algunos principios básicos de política tributaria sobre los cuales construir un nuevo sistema tributario.

Lo primero es tener claro que el objetivo principal de los impuestos es simplemente recaudar lo necesario para el financiamiento del Estado, lo que permite cubrir, entre otras cosas, las necesidades de gasto público (Mirrlees et al. 2010). Adicionalmente, los impuestos pueden ser usados para corregir externalidades negativas cuando no existan regulaciones que sean más eficientes y simples de implementar para lograrlo (Kaplow y Shavell 2002; Mankiw 2008). En consecuencia, los impuestos no deben ser utilizados como una herramienta de política económica como, por ejemplo, para incentivar sectores productivos, zonas geográficas, tecnologías o tipos de organización de la actividad económica. Para eso están otras políticas públicas sectoriales.

Adicionalmente, es importante tener en cuenta que, en general, la distribución de la riqueza y del ingreso no es solo consecuencia de un sistema tributario per se, sino que también del financiamiento y gasto fiscal de distintas políticas públicas. Sin embargo, un impuesto al ingreso progresivo puede jugar un rol importante en redistribuir ingresos (Mirrlees 1971, 1976; Seade 1977; Diamond 1998; Keuschnigg 2011), pero este efecto es un complemento de políticas públicas de gasto social apro- 
piadas para ese propósito (Boadway y Marchand 1995; Cremer y Gavari 1997; Hierro, Gomez-Alvarez y Atienza 2012).

El segundo principio es el de la neutralidad: los impuestos deben ser tan neutrales como sea posible con el fin de evitar distorsiones. En particular, el sistema tributario no debiera introducir incentivos o distorsiones entre distintos sectores económicos, ubicaciones geográficas, fuentes de ingreso, formas distintas de organizar una actividad económica, o entre sus fuentes de financiamiento. Un régimen tributario que respeta este principio garantiza que dos contribuyentes que tienen las mismas rentas deben pagar los mismos impuestos —en clase y monto-, independientemente de la fuente de sus ingresos, o de la forma o lugar en que se haya organizado (Mirrlees 1971; Musgrave 1990; Cordes 1999; Keuschnigg 2011).

Un tercer principio es el de legalidad. Los impuestos deben tener una fuente legal cierta, junto con cumplir con los requisitos de certidumbre y control democrático; también debe ser de fácil y evidente aplicación y entendimiento para el contribuyente. Esto implica que el sistema tributario debe ser simple y con bajo costo - tanto de cumplimiento para los contribuyentes, como de administración y fiscalización para la autoridad tributaria. El cumplimiento tributario no puede ser un impuesto en sí mismo para el contribuyente. La legalidad y la juridicidad de la norma tributaria deben ser resguardados para mantener, también en lo fiscal, la regla de aplicación de la ley o, mejor llamado, el Estado de Derecho, y evitar la indefensión del contribuyente. Al mismo tiempo, debe impedir la impunidad tanto de los contribuyentes que violan las normas, como del fisco que lo persigue abusando en el ejercicio de sus facultades.

Un último principio es que la autoridad tributaria, sin perjuicio de sus amplias facultades de control y fiscalización destinadas a evitar por todos los medios la erosión de la base fiscal, debe ser un órgano al que se le garantice el mayor grado posible de independencia del poder ejecutivo de turno, y asegurar que su acción sea colaborativa y al servicio del contribuyente. Creemos fundamental construir un 'nuevo acuerdo' que restablezca las confianzas entre lo público y lo privado, esto es, entre el contribuyente y el Estado.

Sin duda que podrían potencialmente sumarse una larga lista de parámetros adicionales y más detallados para el diseño de un nuevo siste- 
ma tributario. Sin embargo, creemos que si una amplia mayoría coincide en estos cuatro elementos fundacionales, podremos tener una discusión fiscal fructífera y que tienda a mantener la estabilidad de las reglas del juego. A la vez, este satisfará las necesidades económicas crecientes de un Estado que debe atender demandas sociales cada vez más altas y más sofisticadas en el contexto de una economía abierta a un mundo en cambio permanente y a una evolución tecnológica que avanza vertiginosa e insondablemente.

En ese contexto, este documento es una invitación a pensar, proponer, discutir y delinear un nuevo sistema tributario para Chile, un sistema nuevo transversal y ampliamente discutido y acordado, y que responda a las necesidades del nuevo Chile, proporcionando estabilidad tributaria para el largo plazo.

\section{Elementos estructurales y principios generales de diseño}

El nuevo sistema tributario que se propone se construye sobre dos componentes principales y estructurales: por un lado, un impuesto que grava el ingreso que enriquece al contribuyente, ya sea que se trate de rentas provenientes del capital o del trabajo; y por el otro lado, por un impuesto que grava el consumo de esa riqueza. Adicionalmente, de manera accesoria, se aplican otros impuestos que tienen por objeto desincentivar actividades que producen externalidades económicas o sociales negativas y que no pueden ser desincentivadas por otros medios de manera económicamente más eficiente.

El nuevo sistema tributario trata de ser tan neutral como sea posible, de manera que los regímenes especiales de beneficio a actividades industriales o productivas, zonas geográficas o formas específicas de organizar actividades generadoras de renta o consumo, no son incorporados. La razón fundamental para ello es que los regímenes especiales y exenciones al impuesto al ingreso rompen la neutralidad y generan ineficiencias importantes (Zee 1998; Auerbach y Hasset 1999; McLure 1981).

Asimismo, las aplicaciones discriminatorias de impuestos al consumo no son incluidas, ampliando su base a todo servicio y venta de bienes o derechos, sin distinción. Nuevamente, la razón para ello es que las exenciones y tasas reducidas de impuestos al consumo, como el IVA 
por ejemplo, producen ineficiencias importantes (Creedy 2011; Boadway 2012). Así, el nuevo sistema tampoco considera beneficios impositivos, los que debieran ser reemplazados por subsidios económicos explícitos, justificados por políticas públicas razonables y actualizadas.

Por esta razón es que tampoco se consideran regímenes facilitados de tributación, los que han demostrado contribuir sustantivamente a abrir espacios de erosión de la base imponible. Es así como la evidencia muestra que, por ejemplo, los regímenes especiales y exenciones al impuesto al ingreso producen ineficiencias significativas en magnitud y abren importantes espacios de elusión y evasión (Zee 1998; Auerbach y Hasset 1999; McLure 1981).

Sin perjuicio de lo anterior, y tal como se explica en la sección siguiente, se han considerado elementos de los ingresos anuales del contribuyente secundario y el tamaño de la actividad económica del contribuyente primario, que permiten un tratamiento diferenciado, en ambos casos, solo con el objeto de facilitar el cumplimiento tributario, pero no para crear un régimen de beneficios o incentivos que distorsionen su carga tributaria.

Finalmente, también se propone eliminar las contribuciones de bienes raíces, las patentes de automóviles y el impuesto de timbres y estampillas.

\section{Impuesto a la renta}

En cuanto al impuesto a la renta, este distingue y trata por separado las rentas de los contribuyentes primarios, esto es, personas jurídicas o colectivos de carácter empresarial que son, en mayor medida, la fuente de origen de la generación de rentas a nivel nacional. En paralelo se encuentra el contribuyente secundario o final, que son las personas naturales que obtienen rentas de los anteriores o a partir de su propio trabajo. También se reconoce y trata de manera particular al contribuyente extranjero que no tiene domicilio en Chile, pero que percibe o devenga rentas generadas en el país.

Partiendo por el contribuyente primario, este determinará su renta líquida imponible considerando el total de sus ingresos de base percibi$\mathrm{da}$, y deduciendo sus costos, gastos y gastos efectivos. Sobre esta base de renta líquida se aplicará un impuesto de primera categoría cuya tasa 
será del 30\% y que será considerado crédito en contra del impuesto a la renta que grava al contribuyente secundario. Es importante destacar que la integración del impuesto corporativo con el de las personas es la política tributaria óptima en un impuesto al ingreso (Alt 1983; Gravelle 1999; Gordon 2011). En ese sentido, el impuesto corporativo tiene como único rol precisamente la retención del impuesto al ingreso de las personas (Bird 1996; Gordon 2011; Keuschnigg 2011).

Con el objeto de que todas las utilidades distribuidas desde los contribuyentes primarios a los secundarios estén afectas a impuesto en su origen, y para evitar retiros, remesas o distribuciones con cargo a cantidades que sean consideradas como ingreso no renta o rentas exentas, aquellos retiros, remesas o distribuciones de sumas que no hayan pagado su respectivo impuesto a la renta a nivel de contribuyente primario, serán gravados con un impuesto de igualación de idéntica tasa - 30\%-, que será aplicable a la fecha de su devengo. Dicho impuesto podrá ser utilizado como crédito por el contribuyente primario una vez que se generen las utilidades tributarias afectas a impuesto corporativo, lo cual evita que las diferencias temporales — contables y/o tributarias - resulten gravadas dos veces en el tiempo.

En consecuencia, toda utilidad de un contribuyente primario y todo retiro, remesa o distribución que perciba un contribuyente secundario, habrá siempre pagado impuestos, ya sea el de primera categoría ordinario o el de igualación, y en ambos casos podrá utilizar estos pagos como crédito contra el pago de sus impuestos a las rentas personales.

Dado que se propone igualar las tasas máximas de los impuestos a la renta que afectan al contribuyente primario y secundario con integración total de ambos impuestos, este sistema permite que el foco de fiscalización del impuesto a la renta se centre en su origen, facilitando y bajando el costo de control por parte de la autoridad fiscal (Slemrod 2007; Harberger 2008), pues los impuestos del contribuyente secundario estarán siempre completamente pagados, hayan sido percibidos por este o no.

Una innovación relevante que se propone consiste en introducir un sistema de cumplimiento simplificado: un contribuyente primario con ventas anuales inferiores a 50.000 UF$^{1}$ podrá optar por un sistema

\footnotetext{
${ }^{1}$ Esta sería la categoría de contribuyentes de la pequeña y mediana empresa o PyME.
} 
simplificado de declaración de rentas que será llevado por la misma autoridad tributaria, cuya base se conformará por sus saldos y movimientos de caja, evitándole así el costo y la complejidad de llevar contabilidad por sus propios medios. La autoridad tributaria llevará esta cuenta y libro de caja, alimentando el sistema de registro mediante las anotaciones electrónicas derivadas de la emisión de facturas y boletas electrónicas.

Otra importante innovación que consideramos relevante y se introduce en el nuevo sistema tributario propuesto, con el objeto de facilitar y rebajar significativamente los costos de cumplimiento y fiscalización, es la posibilidad de que grandes contribuyentes que conforman un grupo empresarial o conglomerado financiero, puedan solicitar a la autoridad fiscal que su cumplimiento tributario se haga de manera unificada o consolidada, cumpliendo con estrictos requisitos de transparencia y gestión de riesgo legal.

Por su parte, los contribuyentes secundarios resultarán gravados con una tasa progresiva aplicada sobre el total de las rentas percibidas de contribuyentes primarios generales y otras que les sean atribuidas de contribuyentes primarios PyME, según sea el caso. Si uno de los objetivos del sistema tributario es que contribuya a redistribuir el ingreso y reducir la desigualdad, la forma más eficiente de hacerlo es a través de un impuesto progresivo al ingreso (Atkinson y Stiglitz 1976; Slemrod 1994; Kopzuck 2001; Davies y Hoy 2002; Creedy 2011; Saez 2004; Mirrlees et al. 2010; Boadway 2012).

Para la correcta ponderación del monto de retiros o remesas percibidos desde contribuyentes primarios generales, el monto neto percibido deberá ser incrementado por un factor de normalización que, de manera neutra, incremente la renta atribuida al contribuyente secundario en su monto bruto y no el neto después del pago del impuesto en la fuente, o contribuyente primario.

Esta tasa progresiva que afectará al contribuyente final, sería determinada en función del monto de sus ingresos anuales. Como se señala precedentemente, este impuesto tendrá una tasa máxima de 30\%; los tramos de la escala con tasa marginal positiva han sido reducidos a solo cuatro, se reduce la magnitud de contribuyentes exentos y se incorpora un impuesto negativo, tal como se muestra en la siguiente tabla: 
Tabla 1. ESCALA DE TASAS DEL IMPUESTO AL INGRESO PARA CONTRIBUYENTES FINALES

\begin{tabular}{lccc}
\hline Tramo & Desde (UF) & Hasta (UF) & Tasa marginal (\%) \\
\hline 1 & 0 & 149 & -10 \\
2 & 150 & 749 & 0 \\
3 & 750 & 1.499 & 10 \\
4 & 1.500 & 2.249 & 20 \\
5 & 2.250 & 2.999 & 25 \\
6 & 3.000 & y más & 30 \\
\hline
\end{tabular}

Fuente: Elaboración propia.

Es importante destacar que la progresividad de las tasas parte con una tasa negativa, permitiendo así que el impuesto al ingreso juegue en forma óptima un rol redistributivo (Mirrlees 1971, 1976; Tuomala 1990; Brewer, Saez y Shepard 2010; Jacquet, Lehmann y Van der Linden 2010; Diamond y Saez 2011; Boadway 2012). Esto equivale a que los contribuyentes finales de menores ingresos, no obstante estar obligados a declarar su impuesto a la renta, tendrían una tasa que permitiría recibir una transferencia monetaria equivalente a una devolución de impuestos que, desde un punto de vista económico, social y de política pública contra la pobreza, representa derechamente un subsidio a las familias de los deciles más pobres. Esta es una política exitosa, que se inició en Estados Unidos con el Earned Income Tax Credit en 1975, y que ha sido adoptado en muchos países. ${ }^{2}$ La evidencia muestra que esta es una política con efectos muy positivos en términos de disminución de pobreza y desigualdad, aumento en la participación laboral femenina, mejoría en la salud de padres e hijos, y aumento en la duración del empleo y los ingresos (Hill y Gurley-Calvez 2019; Bastian y Michelmore 2018; Nichols y Rothstein 2016; Eissa y Hoynes 2006; Francesconi, Rainer y Van del Klaauw 2009; Gregg, Harkness y Smith 2009). ${ }^{3}$ Como consecuencia de la implementación de un impuesto negativo, los subsidios directos actualmente existentes en Chile como parte de una política pública de carácter asistencial, debieran ser eliminados y reemplazados por este mecanismo.

\footnotetext{
2 Por ejemplo, en Canadá, Nueva Zelanda, Australia, Finlandia, Bélgica, Austria, Francia, Alemania, Irlanda, Italia, Grecia, Holanda e Inglaterra.

${ }^{3}$ La evidencia para Chile es consistente con estos potenciales efectos positivos. Un impuesto al ingreso negativo podría jugar un rol importante en reducir la desigualdad y en aumentar los ingresos laborales de las personas más pobres (Agostini, Perticará y Selman 2013).
} 
Por razones de neutralidad tributaria, los impuestos al capital y al trabajo son tratados de manera homogénea, de modo de mantener equidad tributaria horizontal y de no generar distorsiones entre las distintas fuentes de ingreso (Mirrlees 1971; Musgrave 1990; Cordes 1999; Mirrlees et al. 2010; Johnson y Myles 2011; Diamond y Saez 2011). En esta línea, el financiamiento de capital con rentas del socio-contribuyente final, es homologado en sus efectos financieros al financiamiento con deuda. Esto es, el financiamiento por deuda permite al contribuyente primario tratar como gasto el monto de intereses pagado; por lo tanto, el financiamiento mediante capital gozará de igual beneficio, aplicándosele un monto de intereses de carácter nocional calculado sobre una tasa de interés de mercado informada por la autoridad fiscal (Bond y Devereux 1995, 2003; Sorensen 2009). ${ }^{4}$ La política de permitir la deducción de una tasa de interés nocional cuando las inversiones se financian con capital en vez de deuda, de tal forma que exista neutralidad tributaria entre deuda y capital para estos efectos, fue planteada por primera vez en un trabajo teórico por Boadway y Bruce (1984) y ha sido implementada con efectos positivos en la inversión en varios países (Bélgica, Italia, Croacia, Suiza, Portugal, Brasil, Malta, Latvia y Chipre).

El nuevo régimen aborda la cuestión del gasto rechazado con una óptica nueva de fuerte acento jurídico, evitando espacios de elusión. Igual enfoque es adoptado respecto de conductas que puedan ser consideradas como abusivas por parte del fiscalizador; esto es, frente a la observación de un gasto por parte de la autoridad, la carga de la prueba de dicha inobservancia recaerá en la misma autoridad.

Asimismo, el sistema incluye la depreciación instantánea como un elemento de base del sistema, con aplicación general, completa y permanente. Sin duda, esta medida tiene un impacto fiscal inicial importante, el cual desaparece en el tiempo, pero constituye un fuerte y poderoso compromiso de política pública a favor de la inversión y el desarrollo económico de todos los sectores productivos del país.

También en línea con el principio de neutralidad y no discriminación entre distintas fuentes de ingreso, las ganancias de capital en la compraventa de bienes o derechos, sin distinción, será considerada

\footnotetext{
${ }^{4}$ En algunos países, este sistema se denomina NID (Notional Interest Deduction) y en otros ACE (Allowance for Corporate Equity).
} 
como renta o ingreso sin deducciones ni beneficios de clase alguna (Slemrod y Yitzhaki 2002; Boadway y Keen 2003; Burman 2010). En consecuencia, el contribuyente primario incluirá esta renta en su base de cálculo general de renta líquida imponible, lo que conduce a una tasa aplicable del 30\%; el contribuyente secundario, por su parte, hará igual cosa, en cuyo caso la tasa aplicable será la que corresponda a su tramo de ingreso. La renta deberá ser efectivamente percibida, de modo que no se entenderá que existen figuras de disposición germinal o 'principio' de enajenación, como se aplica hoy respecto de, por ejemplo, las promesas de compraventa. Por claridad, se hace presente que esto incluye valores de oferta pública e inmuebles por igual.

Salvo por necesidades de implementación del nuevo régimen tributario, el sistema de retenciones y pagos provisionales del impuesto a la renta tendrá una aplicación similar a la actual y los pagos mensuales serán aplicables respecto de todo contribuyente, incluyendo el secundario por sus rentas derivadas del trabajo. La razón para esto es que los impuestos que tienen retención en la fuente disminuyen fuertemente la evasión y la elusión (Andreoni, Erard y Feinstein 1998; Alm 1999; Bloomquist 2003; Slemrod 2007; Kleven et al. 2011), junto con aumentar la eficiencia administrativa (Slemrod 2006; Almunia y Lopez-Rodriguez 2018), por lo que deben ser siempre preferidos en la implementación de un sistema tributario.

Impuestos a rentas económicas no generan distorsiones y por eso es eficiente utilizarlos; ese es el caso de la explotación de recursos naturales, y por esta razón el impuesto a la renta que proponemos incluye un impuesto de carácter especial que afecta las actividades extractivas o intensivas de recursos naturales no renovables (Garnaud y Ross 1983; Heaps y Helliwell 1985; Boadway y Flatters 1993; Lund 2002, 2009; Mirrlees et al. 2010). La operatoria de este impuesto será similar al denominado actualmente royalty a la minería, con una tasa única del $10 \%$ sobre el margen operacional del contribuyente.

En el caso de los contribuyentes extranjeros que obtengan rentas de fuente chilena, si estas corresponden a remesas, retiros o distribuciones de utilidades de contribuyentes primarios, estas resultarán gravadas por regla general con una tasa de impuesto igual a la tasa máxima indicada más arriba -30\%—, impuesto que tendrá el carácter de único y contra el que se podrá usar como crédito el impuesto pagado en la 
fuente. ${ }^{5}$ Ahora, para toda otra renta de fuente chilena devengada por un contribuyente extranjero -incluyendo regalías y contraprestación por derechos de uso, pagos de precio por venta de bienes corporales o incorporales y remuneración por la prestación de servicios-, se aplicará un impuesto adicional del $10 \%$ sobre el total de la renta al extranjero, que tendrá también el carácter de único, pero los impuestos a la renta en la fuente no serán crédito contra este; y de $15 \%$ sobre el pago de intereses sobre créditos otorgados desde el exterior a deudores locales.

Respecto de las rentas de fuente extranjera, estas se incluyen en la base de cálculo de la renta líquida imponible, ya sea del contribuyente primario o del secundario. Con el objeto de aliviar la doble tributación, se reconocerá un crédito por los impuestos pagados en el exterior, sujetos a ciertos límites dependiendo de si las rentas provienen de un país con convenio para evitar la doble imposición vigente con Chile o no. La utilización de créditos se realizará de forma automática, sobre la base de una nómina de impuestos extranjeros que mantendrá la autoridad tributaria.

En el caso de figuras de transferencia de precios y relocalización jurisdiccional de rentas, se seguirán normas similares a las promovidas por la Organización para la Cooperación y el Desarrollo Económico (OCDE).

\section{Impuesto al consumo}

Se propone implementar un impuesto al consumo ampliando su base a toda venta de bienes y derechos de vendedores habituales -incluyendo los inmuebles sin excepción-, y a toda prestación de servicios -incluyendo los financieros sin distinción, como así también los de salud y educacionales-, eliminando de este modo exenciones que generan ineficiencias y además aumentan tanto la evasión como los costos de administración y fiscalización (Creedy 2011; Boadway 2012). ${ }^{6}$ La tasa del

\footnotetext{
${ }^{5}$ Australia tiene exactamente el mismo sistema: una tasa general de impuesto corporativo de $30 \%$ y un impuesto a los dividendos con la misma tasa, con crédito por el impuesto corporativo.

${ }^{6}$ Si bien la intención de muchas de las exenciones es hacer menos regresivo un impuesto al consumo, es una forma ineficiente de hacerlo porque favorece en mayor proporción a contribuyentes de altos ingresos que consumen bienes más caros. Si el objetivo es redistribuir, es mejor opción tener la misma tasa de impuestos para todos los bienes que no generan externalidades negativas y utilizar un impuesto progresivo no-lineal al ingreso para redistribuir (Laroque 2005; Kaplow 2006; Sorensen 2007; Gauthier y Laroque 2009; Keen y Smith 2006; Bye, Strom y Avitsland 2012).
} 
impuesto al consumo (IC) será de un 15\% sobre el valor del bien o servicio efectivamente pagado.

La base de cálculo del impuesto será calculada siguiendo reglas similares a las contempladas actualmente en la ley del Impuesto al Valor Agregado (IVA). Sin perjuicio de lo anterior, atendida la ampliación conceptual del hecho gravado relacionado con la prestación de servicios, los contribuyentes se verán obligados a llevar contabilidad. Para facilitar este trámite, los contribuyentes personas naturales y extranjeros podrán optar entre (i) pagar el impuesto sobre la base de un libro de compras y ventas, determinando su crédito fiscal sobre la base efectiva de los bienes adquiridos y servicios contratados, o (ii) declarar y pagar su débito fiscal aplicando un crédito fiscal presunto equivalente a multiplicar el débito fiscal por el factor 0,3. De cualquier forma, los contribuyentes persona natural podrán optar por acogerse a la proposición de impuesto que la autoridad fiscal les haga mensualmente sobre la base de sus registros electrónicos de emisión de boletas y facturas, lo que les permitirá evitar llevar contabilidad para estos solos efectos.

En cuanto a ciertos tipos de actividades comerciales virtuales o sobre plataformas electrónicas, cabe hacer presente que los servicios prestados y bienes vendidos en Chile estarán gravados con impuesto al consumo, aunque sean pagados en el extranjero a través de terceros. Las comisiones aplicadas por establecimientos que facilitan el pago de estos servicios o bienes estarán también afectas a este impuesto al consumo. El pago efectuado por la empresa que presta la plataforma de pago al proveedor del bien o servicio no estará afecto a este impuesto por tratarse simplemente del efecto de un mandato. Los bienes adquiridos o los servicios prestados desde el extranjero, pero para ser gozados por un contribuyente chileno y pagado desde Chile, estarán afectos a impuesto al consumo solo en el caso de que dicho pago no sea tratado para efectos del impuesto a la renta.

Adicionalmente, los precios de venta al detalle cobrados al consumidor deberán exhibir separadamente el monto del impuesto y el precio neto de venta. De esta forma, el contribuyente tomará conciencia del pago y del monto del impuesto, lo que es especialmente relevante como una medida de responsabilidad y madurez fiscal y social. 


\section{Impuestos especiales}

El nuevo sistema tributario no considera la existencia de impuestos al crédito o de timbres y estampillas. También se derogan los impuestos sobre premios de lotería e ingresos; estos últimos pasarán a ser tratados como renta ordinaria del contribuyente respectivo, precisamente en la lógica de no discriminar entre fuentes de ingreso.

Por otro lado, en la necesidad de eliminar las externalidades negativas de la combustión de hidrocarburos y la leña, se introduce un nuevo tributo con foco en el combustible propiamente tal y en el agente de combustión, tales como motores, calderas o cocinas. El contribuyente de este impuesto es el comprador primario del combustible, cuyo pago será retenido por el vendedor; la tasa del impuesto será equivalente a 0,01\% de una Unidad Tributaria Anual (UTA), multiplicado por el coeficiente de generación contaminante del aparato o combustible, el que será determinado por decreto conjunto de los ministerios de Energía, de Medio Ambiente, y de Transporte y Telecomunicaciones. Este tipo de impuestos permite reducir las externalidades negativas asociadas a la contaminación ambiental para, así, mejorar la asignación de recursos en la economía. En ese sentido, se trata de impuestos correctivos que deben implementarse independientemente de las necesidades de recaudación (Portney et al. 2003; West y Williams 2004; Bento et al. 2005).

En la misma línea, se introduce un nuevo impuesto con el objeto de eliminar las externalidades negativas provenientes del consumo de sustancias que, documentada y fehacientemente, se ha concluido que son dañinas para la salud humana y adicionalmente generan un alto gasto público destinado a hacerse cargo de los efectos nocivos de su consumo. Este tributo gravará el consumo de las sustancias que, para efectos de este impuesto, serán determinadas por decreto supremo, pero que incluirán, al menos, el alcohol presente en cualquier tipo de bebida, el azúcar pura o adicionada en alimentos, el cloruro de sodio en alimentos procesados, las grasas saturadas en cualquier forma o estado de procesamiento y los derivados del tabaco. El contribuyente de este impuesto es el comprador primario de la sustancia nociva, cuyo pago será retenido por el vendedor, si fuere el caso. La tasa del impuesto será equivalente a 0,01\% de una Unidad Tributaria Anual, multiplicado por el coeficiente de concentración de la sustancia nociva en la bebida o alimento que corres- 
ponda, el que será determinado por decreto conjunto de los ministerios de Hacienda y de Salud.

Por otro lado, se establecerá un impuesto especial que gravará la renta proveniente de actividades extractivas y/o intensivas en el uso de recursos naturales no renovables. Es importante mencionar que este tipo de impuesto afecta a las rentas económicas y, por lo tanto, no genera distorsiones y por eso mismo es eficiente utilizarlo (Heaps y Helliwell 1985. Las actividades afectas a este impuesto serán determinadas por decreto supremo e incluirán, al menos, las sustancias minerales metálicas y no metálicas (concesibles) presentes en el territorio nacional y en el suelo marino correspondiente a la zona de aprovechamiento exclusivo de Chile. Adicionalmente, incluirá los espectros radioeléctricos y el uso de volúmenes de aguas dulces o saladas de mares, lagos y ríos navegables. El impuesto se calculará considerando los precios internacionalmente conocidos para los bienes extraídos o explotados, y los costos del contribuyente. La tasa del impuesto será fluctuante en función del nivel de producción o extracción, e irá entre el 3\% y el 10\% sobre el margen operacional del contribuyente afecto, que es la base correcta para este tipo de impuesto, tal como se ha mostrado en la literatura académica (Boadway y Bruce 1984; Bond y Deveraux 1995; Boadway y Keen 2003. Las normas del detalle de aplicación de este impuesto especial a la renta serán similares al actualmente aplicable a la gran minería del cobre. Para el caso de los espectros radioeléctricos y los volúmenes de agua, se aplicará un sistema de licitación que permita asignar el uso y la explotación de estos bienes con justicia, y asegurando su preservación sustentable.

\section{Impuestos de base geográfica}

No existirán impuestos regionales in municipales, pero con el objeto de financiar efectivamente y en forma estable la descentralización, existirá una Ley de Rentas Regionales que considerará contribuciones a los distintos municipios de su competencia, en conformidad con las participaciones de estos en las bases de cálculo de los impuestos generales y en coordinación con el presupuesto anual de la nación.

El impuesto al dominio inmobiliario o contribuciones será derogado, pues si el fundamento de este impuesto se encuentra en la participación que le corresponde al fisco en la plusvalía de que se beneficia 
el propietario del inmueble - a partir de las inversiones sociales y de infraestructura pública que financia o coordina el Estado-, esta renta es efectivamente capturada por el propietario del inmueble con ocasión de la enajenación del bien, en cuyo caso deberá pagar impuestos a la renta por toda la ganancia de capital percibida y sobre la que el fisco ya tiene un medio para participar.

Por otro lado, también el impuesto a los vehículos motorizados o patente será derogado pues, convenida la aplicación de un impuesto a la combustión de hidrocarburos y al comercio de combustibles, el fundamento del impuesto a los vehículos motorizados o patente no puede ser otro sino el uso y ocupación de las vías, cuya construcción ha sido financiado por el erario fiscal, lo que puede ser más económica y eficientemente regulado mediante un adecuado sistema de tarificación vial.

\section{Beneficios y exenciones}

En el nuevo régimen tributario no existirán sistemas de contabilidad simplificada y se derogarán los regímenes especiales existentes (como, por ejemplo, la renta presunta), lo mismo que las leyes de fomento territorial y de zonas francas que serán derogadas. La evidencia internacional muestra que los regímenes especiales geográficos, como zonas francas o parques industriales, no generan más empleos ni atraen más inversión, y sí generan espacios de evasión y elusión importantes (Papke 1991; Boarnet y Bogart 1996; Peters y Fisher 2002; Couch y Barret 2004). También se derogarán los demás programas de fomento en base a excepciones, franquicias tributarias o subsidios a impositivos, a cualquier actividad extractiva, industrial o comercial.

\section{Impuestos al patrimonio}

No somos de la opinión de introducir un impuesto general al patrimonio. En primer lugar, porque el país necesita fortalecer la capacidad de ahorro de los agentes privados para que este se traduzca en mayor inversión y, con ello, se fomente el ciclo de producción y desarrollo económico. Solo de esta forma se logrará incrementar el producto interno y disponer de mayores recursos para redistribución. La evidencia es que un impuesto al 
patrimonio atenta contra ese objetivo, ya que genera efectos negativos importantes en el crecimiento económico (Pichet 2007; Hansson 2010; Fuest et al. 2018), en el empleo y en la disponibilidad de capital para emprendedores (Hansson 2008). En segundo lugar, la experiencia internacional muestra que los países que intentaron implementarlos han ido progresivamente desmantelándolos hasta eliminarlos por completo, ${ }^{7}$ ya que además es un impuesto que recauda poco, tiene alta tasa de evasión (Seim 2017; Brulhart et al. 2019), y tiene grandes costos de fiscalización y administración. Por último, un impuesto al patrimonio genera distorsiones e ineficiencias importantes, las cuales en magnitud pueden ser muy superiores a su potencial recaudación (Pichet 2007).

El impuesto a las donaciones y herencias se focaliza en el traspaso intergeneracional. La herencia es tratada como un hecho de carácter contable. De ahí se siguen consecuencias relevantes si el destino final del traspaso es la obtención de una renta ordinaria para el heredero o asignatario. En consecuencia, la herencia recibida es una renta gravada con el impuesto de su especie cuando esta sea realizada (enajenación onerosa). Dado que no tiene costo tributario para el heredero, toda la herencia será renta, a menos que el causante fije su costo y lo haga heredable, adelantando el pago del impuesto a la renta sobre su costo a la fecha del adelanto. Los bienes valorizados a mercado o en efectivo —equivalentes a efectivo - pagarán impuesto a la renta contra su percepción.

Por su parte, las donaciones son tratadas como tales y el sistema reconoce diferencias para el caso de una transferencia corporativa con fines de interés público, caridad o altruismo, de las que solo tienen por causa la mera liberalidad del donante o la relocalización de sus activos o estructuras de organización patrimonial. Finalmente, las donaciones como un todo, sin perjuicio de su finalidad, son abordadas a partir de un nuevo tratamiento integral de donaciones, en lugar del tratamiento segregado que tienen hoy en distintas leyes y decretos de difícil aplicación.

\footnotetext{
${ }^{7}$ Países en la OCDE que tuvieron impuestos a la riqueza y los eliminaron (la fecha de derogación se indica entre paréntesis) son: Finlandia (2006), Suecia (2007), Austria (1994), Alemania (1997), Dinamarca (1997), Francia (2017), Holanda (2001), Irlanda (1978), Islandia (2006) y Luxemburgo (2006).
} 


\section{Institucionalidad y jurisdicción}

La implementación de un nuevo régimen tributario debe ir aparejada con el establecimiento de instituciones que estén a la par de las modernizaciones introducidas, así como de los requerimientos económicos y administrativos de un país dinámico y en progreso. Los parámetros de diseño para la nueva institucionalidad tributaria son los siguientes:

(a) Independencia: Las autoridades de los poderes del Estado no podrán influir determinantemente en la actuación de la nueva institucionalidad, salvo en las instancias y casos previstos especialmente por la ley.

(b) Colaboración público-privada (buena fe y servicio al contribuyente): La relación entre el fisco y el contribuyente debe basarse en la confianza mutua, la cual se ampara en la presunción de buena fe y se define orgánicamente como una plataforma de servicio, ayuda y apoyo al contribuyente.

(c) Juridicidad y armonía regulatoria: Las potestades regulatorias e interpretativas de la nueva institucionalidad tributaria deben ser ejercidas en estricto apego al Estado de Derecho y preservando una armonía regulatoria con los demás órdenes jurídicos.

(d) Eficiencia administrativa: La administración tributaria y la fiscalización deben ser llevadas adelante evitando el uso dispendioso de recursos públicos y la duplicidad de funciones. Esto conlleva el consolidar organismos complementarios para que estos queden bajo la competencia de una autoridad centralizada. Asimismo, la nueva institucionalidad debe contar con facultades de organización interna lo suficientemente flexibles como para permitir adaptarse a nuevas condiciones de gestión y a la retención de talentos.

(e) Especialidad técnica: La función tributaria es compleja y constituye un ámbito especializado tanto de la administración pública como del orden jurídico.

(f) Monopolio nacional de la fiscalización y el cobro: La autoridad tributaria central mantendrá el monopolio de la fiscalización tributaria, de su cobro y recaudación, generándose una cuenta de alcance en favor de los gobiernos regionales. Esta será traspasada neta de los costos generales de fiscalización y cobranza, los que deberán ser proporcionalmente compartidos. 
(g) Cumplimiento facilitado y de bajo costo: El cumplimiento tributario no puede convertirse en una carga en sí mismo. La simplicidad de los trámites y la facilitación de medios electrónicos y en línea son parte de las obligaciones principales de la autoridad tributaria.

\section{Autoridad fiscal}

Con el nombre de Servicio al Contribuyente para la Administración y Recaudación Tributaria (SCART), se creará una entidad especializada e independiente del poder ejecutivo, que tendrá a su cargo la fiscalización, administración, cobro y recaudación de todo tributo, y con rango constitucional. EI SCART tendrá facultades reglamentarias e interpretativas y podrá, asimismo, conducir investigaciones y planes de fiscalización, así como girar en contra de un contribuyente el monto de impuestos impagos si estos le fueren exigibles. Adicionalmente, representará judicialmente el interés fiscal en la persecución de tributos impagos. En su definición orgánica, el SCART deberá constituirse como una entidad al servicio del contribuyente, en miras de apoyar y facilitar su cumplimiento tributario.

La dirección superior del SCART estará a cargo de un consejo directivo, cuyos miembros deberán ser expertos de irreprochable reputación. Serán nombrados por distintos poderes y cuerpos de la sociedad civil, a partir de propuestas emanadas del Consejo de Alta Dirección Pública. El SCART contará también con un auditor fiscal jefe, quien tendrá a su cargo la responsabilidad de conducir investigaciones concernientes a la violación de las normas de cumplimiento tributario, dotado de potestades fiscalizadoras incluso de carácter intrusivo, similares a las que le caben al fiscal de la Comisión para el Mercado Financiero.

EI SCART podrá liquidar el pago de impuestos adeudados y a la falta de pago se pasarán los antecedentes al auditor fiscal jefe para que conduzca las acciones civiles de cobro; si llegare a la convicción de existir delitos, pondrá los antecedentes en conocimiento del Consejo para que este resuelva, en votación secreta, el ejercicio de la acción penal. Con dicho acuerdo se presentará la querella respectiva y se entregarán todos los antecedentes recabados al Ministerio Público, el que estará obligado a formalizar al contribuyente imputable. 
EI SCART tendrá la facultad exclusiva y privativa de interpretar administrativamente la ley tributaria. Conforme lo anterior, podrá emitir regulaciones de aplicación general en materia tributaria y aduanera, como asimismo absolver consultas de los contribuyentes sobre temas de aplicación particular, pero respecto de las que los demás contribuyentes podrán acogerse de buena fe si los elementos de contexto fueren análogos. Previo a cualquier nueva regulación, el SCART deberá someter los antecedentes a discusión pública para recibir iniciativas o sugerencias, con la obligación de responder pública y fundadamente su adopción o rechazo.

El SCART Ilevará adelante las funciones de superior control del cumplimiento tributario de los contribuyentes, tanto de obligaciones de información que el contribuyente debe proveer a la autoridad tributaria, como respecto del pago de impuestos devengados y derechos de aduana.

EI SCART deberá preferir la implementación de registros y formularios de cumplimiento sobre plataformas electrónicas que la misma autoridad tributaria pondrá a disposición del contribuyente.

La liquidación y giro de tributos podrá ser incrementada con la imposición de multas e intereses a beneficio fiscal que, en casos de ostensible mala fe, podrán llegar incluso hasta tasas más altas aplicadas sobre el total de los impuestos adeudados más intereses, de tal forma de desincentivar la evasión tributaria.

\section{Justicia tributaria y aduanera}

Contra la liquidación y el giro de tributos solo cabe la reclamación tributaria interpuesta frente al Tribunal Tributario y Aduanero competente, sujeto al análisis de suficiencia formal y de plausibilidad, y la presentación de un bono de seriedad que podrá constituirse en la forma de una boleta bancaria de garantía contra el resultado de la contienda. La acción de reclamación se tramitará como juicio sumario; agotado el debate, el juez llamará a las partes a conciliación por un amigable componedor experto. A la falta de conciliación, se dictará el auto de prueba; agotado el probatorio, las partes oirán sentencia. Contra la sentencia de primera instancia solo cabe el recurso de apelación tributaria que deberá ser presentado frente a la Corte de Apelación Tributaria y contra el 
fallo de esta, solo cabrán los recursos de casación y queja ante la Corte Suprema.

La Corte de Apelación Tributaria estará integrada por cinco miembros designados por la Corte Suprema, a partir de la terna que para cada integrante haga el Consejo de Alta Dirección Pública, considerando a expertos en derecho tributario y aduanero, contabilidad o auditoría tributaria, finanzas, negocios y administración de empresas, o administración pública. A su turno, la Corte Suprema deberá organizar una sala especializada y permanente de asuntos tributarios y aduaneros.

Se establecerá, también, una Defensoría del Contribuyente. Esta velará por sus derechos, estableciendo canales de asistencia y apoyo litigioso; también recibirá los reclamos de los contribuyentes para procesarlos según su mérito y en conformidad con las reglas que se dará el SCART para estos efectos.

En cuanto a facultades especiales para evitar la evasión, la erosión de la base imponible y la traslación de rentas, el SCART tendrá entre sus facultades de control y fiscalización, la capacidad de tasar las prestaciones mutuas de actos jurídicos onerosos. Asimismo, tendrá la facultad de recalificar el objeto de actos jurídicos de relevancia para la determinación de la base de cálculo de un impuesto o la tasa que le sería aplicable. Tales determinaciones deberán sujetarse a condiciones de equidad y mercado razonables para el bien o servicio de que se trate, y puesto en el momento y en el contexto comercial que sea correspondiente. Las recaracterizaciones jurídicas deberán observar un estricto apego al derecho ordinario que les sea aplicable y, en cualquier caso, el contribuyente tendrá la facultad de reclamar de tales calificaciones ante los tribunales tributarios y aduaneros competentes. Por otra parte, la ley reconocerá la legitimidad de los contribuyentes de ampararse en la economía de opción como causa inmediata de sus actos jurídicos singulares o complejos que conlleven efectos de relevancia tributaria, estableciendo parámetros legales preclaros para dicha función y distinguiéndola sin espacio a dudas de figuras elusivas, cuyos parámetros conceptuales también serán definidos por ley, y en ambos casos siguiendo fielmente las recomendaciones de la OCDE.

El actual Servicio Nacional de Aduanas y la Tesorería General de la República serán integrados y consolidados bajo el SCART, organismo que consolidará todas estas entidades, funciones, patrimonio y plantel humano. 


\section{Efectos recaudatorios}

El ideal sería poder tener microdatos de contribuyentes, tanto personas como empresas, para poder simular detalladamente la propuesta tributaria que se propone en este trabajo y así obtener una estimación precisa respecto de la recaudación tributaria que generaría. Sin embargo, no fue posible obtener acceso a ese tipo de datos o al menos a una muestra representativa de contribuyentes que hiciera factible el análisis. Por esta razón, con el objeto de tener al menos una aproximación razonable, aunque imprecisa, respecto de la potencial recaudación que generaría la propuesta, se consideraron datos agregados de recaudación y base imponible para cada impuesto, junto a la evidencia académica, en el caso en que existiera, con respecto al impacto de la tasa de impuestos sobre la base tributaria. En general, la metodología utilizada para estos efectos considera el cambio en la recaudación actual ante una modificación en la tasa o en la base del impuesto. La recaudación (R) que genera un impuesto es simplemente la tasa de impuesto (t) por la base (B) del impuesto:

$$
R=t * B
$$

La base tributaria varía para cada tipo de impuesto. En el caso de los impuestos específicos, como el impuesto a los combustibles, por ejemplo, la base es la cantidad vendida (metros cúbicos de combustibles). En el caso de los impuestos ad valorem, como el de los alcoholes, por ejemplo, la base son las ventas totales (precio por cantidad vendida). En el caso del impuesto al ingreso, la base para las empresas son sus utilidades y para las personas sus ingresos totales (en ambos casos menos las exenciones y los ingresos no renta). Es importante mencionar que la base del impuesto, definida por la ley, se ve afectada por la evasión y la elusión tributaria. Esa es la razón por la cual la recaudación efectiva es distinta a la recaudación potencial. Para efectos de las estimaciones realizadas, se consideró la base efectiva de cada impuesto, la cual ya considera los efectos de evasión y elusión. Al utilizar la base efectiva, implícitamente se asume que los niveles de evasión y elusión se mantienen constantes e idénticos a los actuales.

Al cambiar la tasa de impuesto, dejando la base del mismo impuesto y todos los otros impuestos constantes, el efecto en la recaudación se obtiene al diferenciar totalmente la ecuación (1): 


$$
d R=B * d t+\frac{\partial t}{\partial t} d t
$$

El primer término al lado derecho de la igualdad captura el efecto directo del cambio en la tasa sobre la base existente y el segundo término captura el efecto que tiene el cambio en la tasa sobre la base del impuesto. Por ejemplo, un aumento de $\$ 100$ por metro cúbico $(d t=100$ en este caso) en el impuesto a los combustibles tiene dos efectos que son precisamente los que capturan estos dos términos en la ecuación (2). El primero es que aumentaría la recaudación directamente en \$100 por cada metro cúbico actualmente vendido ( $\left.B^{*} 100\right)$. El segundo es que la base se reduce porque, ante el aumento en el impuesto (y como consecuencia en el precio), se venden menos metros cúbicos de combustible que antes. El efecto final en la recaudación es el efecto neto de ambos términos.

Estimar el primer término para cada impuesto es relativamente simple, basta con tener datos de la base de cada impuesto y considerar la magnitud deseada en el cambio en la tasa del impuesto. En cambio, estimar el segundo término es bastante más complejo, ya que se requiere estimar el efecto que tiene el cambio en la tasa del impuesto en la base del impuesto (cantidades, ventas, ingresos). Por ejemplo, en el caso de impuestos a los bienes, esto implica estimar primero cuál es el efecto del impuesto en los precios y luego el efecto de los precios en la cantidad que se vende del bien en el mercado. En la literatura académica existen estimaciones para este segundo efecto en el caso de los cigarrillos, los combustibles y los alimentos que contienen azúcares, sal y grasas saturadas. En cada uno de los impuestos asociados a esos bienes se utilizó la estimación relevante en la literatura con el objetivo de cuantificar el segundo término en la ecuación (2). En todos los otros casos, ante la falta de estimaciones para este efecto, se asumió que el efecto es cero. En otras palabras, se asumió que la base del impuesto no cambia ante una modificación en la tasa del impuesto. Sin duda, este supuesto es poco realista y por esta razón es necesario explicitar la interpretación correcta de la estimación para estos casos. Dado que un aumento de impuestos, en general, reduce la base del impuesto, una estimación que no considera el segundo término en la ecuación (2) debe interpretarse como el aumento máximo posible en la recaudación ante el aumento en la tasa. 
En grandes números, en base a la metodología general descrita y los datos agregados disponibles del Servicio de Impuestos Internos respecto de la recaudación actual de cada tipo de impuestos y el número de contribuyentes por tramo de ingreso, junto a la evidencia existente en trabajos académicos para Chile para distintos tipos de impuestos, las estimaciones preliminares de recaudación tributaria que el nuevo régimen conllevaría son las siguientes:

Tabla 2. RECAUDACIÓN POTENCIAL DEL NUEVO RÉGIMENTRIBUTARIO PROPUESTO

\begin{tabular}{lr}
\hline Recaudación estimada (millones US\$*) & 22.328 \\
\hline Impuesto al consumo & \\
Impuestos al ingreso: & 10.490 \\
Contribuyentes primarios (empresas) & 6.090 \\
Contribuyentes secundarios (individuos) & 2.588 \\
Extranjeros & -382 \\
Impuesto negativo & \\
Otros impuestos: & 1.460 \\
Tabaco & 196 \\
Alcoholes & 430 \\
Azúcares, sal, grasas saturadas & 4.093 \\
Combustibles y combustión $\left(\mathrm{CO}_{2}\right)$ & 672 \\
RR.NN. no renovables (10\%) & 47.965 \\
\hline Total & \\
\hline
\end{tabular}

Fuente: Datos de recaudación tributaria del SII; Agostini, Engel, Repetto y Vergara (2018); Agostini, Corvalán, Cuadrado, Martínez y Paraje (2018); Agostini, Perticará, Selman (2013); Agostini (2012, 2017); Servicio de Impuestos Internos (2019).

Estas estimaciones se basan en las consideraciones de diseño y en la metodología general que se han descrito anteriormente, pero es importante detallar y destacar más específicamente lo siguiente:

- El sistema de royalty sobre los recursos naturales no renovables considerado en esta propuesta es más amplio que el actualmente aplicable a la gran minería. Para efectos de estos cálculos, solo hemos tomado la recaudación histórica de dicho impuesto y ajustado la tasa del impuesto, utilizando un criterio conservador dada la falta de antecedentes muestrales sólidos. En otras palabras, se mantuvo la base constante y se 
aumentó la tasa del royalty. Un cálculo más preciso debiera considerar el aumento en la base del impuesto.

- No existen datos robustos para hacer estimaciones serias respecto del nuevo impuesto a la contaminación, en que el foco apunta a los combustibles y medios de combustión. Por ello, conservadoramente hemos preferido mantener las cifras de recaudación histórica por impuesto a los combustibles y aplicar solamente el cambio de tasa.

- No se incluyen aquí los efectos de ampliar la aplicación del impuesto a la renta sobre las ganancias de capital en la compraventa de valores mobiliarios e inmuebles por no contar con antecedentes técnicos y datos que permitan obtener una estimación recaudatoria razonable de esta medida. Se considera, entonces, una recaudación de cero, lo cual es irreal, pero cualquier estimación con los pocos datos disponibles no tiene validez alguna.

- La aplicación de medidas de automatización electrónica en línea para la emisión de boletas y facturas tampoco ha sido considerada por no contar con datos y evidencia consistente que permitan estimar la recaudación producto de esta medida. Se considera una recaudación de cero, a pesar de que debiera ser positiva.

- Las estimaciones de recaudación del impuesto al ingreso - para contribuyentes primarios y secundarios - se basan en las actuales recaudaciones de los impuestos de primera y segunda categoría, ajustadas a las nuevas tasas y tramos de ingresos, considerando el número de contribuyentes por tramo de ingreso. Para la eliminación de los regímenes especiales se consideró la recaudación estimada por el Servicio de Impuestos Internos en su informe anual de gastos tributarios.

- El costo estimado para el 'impuesto negativo' se basa en la misma metodología y en datos utilizados en Agostini, Perticará, Selman (2013), pero fue actualizado a 2018.

- El ingreso estimado para el 'impuesto a azúcares, sal y grasas saturadas' se basa en la metodología y datos utilizados en Agostini, Corvalán, Cuadrado, Martínez y Paraje (2018).

\section{Conclusiones}

Uno de los roles que puede jugar el sistema tributario en países con alta desigualdad como Chile, es contribuir a redistribuir el ingreso en forma 
complementaria al rol que juegan las políticas sociales focalizadas. Ese es uno de los roles específicos que solo el impuesto al ingreso puede jugar dentro de un sistema tributario. En este sentido, el régimen tributario que se propone establece bases de impuesto, tramos de ingreso y tasas marginales de impuesto al ingreso que contribuyen en esa dimensión. Adicionalmente, permite hacer de forma más eficiente la fiscalización y administración del cumplimiento tributario, facilitando las tareas a los contribuyentes y desincentivando la erosión en la base tributable o la elusión impositiva, lo que se logra al eliminar brechas en donde el arbitraje de tasas y bases tributarias permitía obtener rentas anormales si se contaba con la tecnología jurídica y contable para lograrlo. Así, los impuestos finales serán más bajos - lo que podría inducir a creer equivocadamente que beneficia a los más ricos-, pero la verdad es que los impuestos se pagarán efectivamente y en la fuente, lo que permite que las tasas efectivas sean más altas en la medida en que aumentan los ingresos y el sistema sea efectivamente progresivo. De nada sirve contar con tasas altas si es que estas, en la práctica, por evasión o elusión, no se pagan.

La rebaja significativa de la tasa de impuesto al consumo es un factor que debe destacarse en la propuesta. El IVA es un impuesto regresivo; pero es un impuesto de tan fácil recaudación que es tentador utilizarlo lo más posible y es así como representa casi el 50\% de la recaudación tributaria en Chile. En esta propuesta, los pobres y la clase media pagarán proporcionalmente menos impuestos, y eso es un logro que creemos debe atesorarse y preservarse.

Es importante destacar también que esta propuesta considera la implementación de impuestos a las externalidades negativas que generan tanto el consumo de algunos bienes - alcohol, cigarrillos, sal, grasas saturadas y azúcar - como el uso de insumos — diésel y gasolinas. Este tipo de impuestos tiene la doble virtud de generar recaudación y de mejorar la asignación de recursos en la economía.

En términos distributivos, la propuesta permite desplegar todo el potencial que tienen los impuestos para redistribuir el ingreso y disminuir la desigualdad, al considerar un impuesto al ingreso progresivo y de base amplia, que logra que efectivamente quienes tienen mayores ingresos contribuyan en mayor medida a financiar al Estado. Asimismo, contempla un impuesto negativo al ingreso que complementa en forma 
eficiente y con los incentivos correctos las políticas sociales que benefician a las personas de menores ingresos.

Por último, la crisis institucional y de confianza por la que atraviesa el Chile actual también tiene su correlato tributario. La desconfianza mutua entre el contribuyente y la autoridad fiscal es insostenible para una sana convivencia social y para el adecuado desarrollo económico y productivo. La propuesta que presentamos ataca el fondo del problema, generando un nuevo paradigma de pacto público-privado fundado en certeza jurídica y en transparente independencia.

Finalmente, hacemos una invitación a dialogar, a debatir, a poner preguntas en la mesa. No hay que ser experto para tener el derecho a cuestionarse y esperamos que se propongan nuevas ideas, aunque parezcan estrafalarias. De la reflexión y la falta de prejuicios provienen los avances y las innovaciones más relevantes: ¿por qué no es posible hacer las cosas de una manera distinta? Nosotros creemos que sí lo es.

\section{Bibliografía}

Agostini, C.A. 2012. Incidencia tributaria en el mercado de las gasolinas en Chile. Revista de Análisis Económico 27(2), 53-73.

Agostini, C.A. 2013. Una reforma eficiente y equitativa del impuesto al ingreso para Chile (199-246). En Arellano, J.P. y Corbo, V. (eds.), Tributación para el desarrollo: estudios para la reforma del sistema chileno. Santiago: Uqbar Editores.

Agostini, C.A. 2017. Impuesto a los cigarrillos en Chile: una propuesta. Economía y Política 4(2), 37-60.

Agostini, C.A., Perticará, M. y Selman, J. 2013. Una propuesta de crédito tributario al ingreso para Chile. Estudios Públicos 129, 49-104. Disponible en: https://www. cepchile.cl/cep/site/docs/20160304/20160304100211/rev129_CAgostiniJSelman-MPerticara.pdf [30 de noviembre 2020].

Agostini, C.A. y Martínez, C. 2014. Response of Tax Credit Claims to Tax Enforcement: Evidence from a Quasi-Experiment in Chile. Fiscal Studies 35(1), 41-65.

Agostini, C.A., Martínez, C. y Flores, B. 2012. Distributional Effects of Eliminating the Differential Tax Treatment of Business and Personal Income in Chile. CEPAL Review 108, 175-201.

Agostini, C.A., Corvalán, C., Cuadrado, C., Martínez, C. y Paraje, G. 2018. Evaluación y aplicación de impuestos a los alimentos con nutrientes dañinos para la salud en Chile. Banco Interamericano de Desarrollo. Disponible en: https://www. researchgate.net/publication/323692690_Evaluacion_y_Aplicacion_de_ Impuestos_a_los_Alimentos_con_Nutrientes_Daninos_para_la_Salud_en_Chile [30 de noviembre 2020].

Agostini, C.A., Engel, E., Repetto, A. y Vergara, D. 2018. Using Small Business for Individual Tax Planning: Evidence on the Impact of Special Tax Regimes in Chile. International Tax and Public Finance 25(6), 1449-1489. 
Alavoutunki, K., Haapanen, M. y Pirttila, J. 2017. The Consequences of the Value-Added Tax on Inequality. CEsifo Working Paper 6318.

Alm, J. 1999. What is an Optimal Tax System? (363-380). En Slemrod, J. (ed.), Tax Policy in the Real World. Cambridge: Cambridge University Press.

Alm, J. 2012. Measuring, Explaining, and Controlling Tax Evasion: Lessons from Theory, Experiments, and Field Studies. International Tax and Public Finance 19(1), 54-77.

Almunia, M. y Lopez-Rodriguez, D. 2018. Under the Radar: The Effects of Monitoring Firms on Tax Compliance. American Economic Journal: Economic Policy 10(1), 1-38.

Alt, J.E. 1983. The Evolution of Tax Structures. Public Choice 41(1), 181-222.

Andreoni, J., Erard, B. y Feinstein, J. 1998. Tax Compliance. Journal of Economic Literature 36(2), 818-860.

Atkinson, A.B. y Stiglitz, J.E. 1976. The Design of Tax Structure: Direct Versus Indirect Taxation. Journal of Public Economics 6(1-2), 55-75.

Auerbach, A.B. y Hasset, K. 1999. Tax Policy and Business Fixed Investment in the United States. Journal of Public Economics 47(2), 141-170.

Bastian, J. y Michelmore, K. 2018. The Long-Term Impact of the Earned Income Tax Credit on Children's Education and Employment Outcomes. Journal of Labor Economics 36(4), 1127-1163.

Bento, A.M., Goulder, L.H., Henry, E., Jacobsen, M.R. y Von Haefen, R.H. 2005. Distributional and Efficiency Impacts of Increased US Gasoline Taxes: An Econometrically based Multi-Market Study. American Economic Review 95(2), 282-287.

Besley, T. y Persson, T. 2014. Why Do Developing Countries Tax So Little? Journal of Economic Perspectives 28(4), 99-120.

Bird, R. 1996. Why Tax Corporations? International Centre for Tax Studies, University of Toronto, Working Paper 96-2.

Bloomquist, K.M. 2003. Tax Evasion, Income Inequality, and Opportunity Cost of Compliance. Proceedings. Annual Conference on Taxation and Minutes of the Annual Meeting of the National Tax Association 96, 91-104.

Boadway, R. 2012. From Optimal Tax Theory to Tax Policy. Cambridge, MA: MIT Press.

Boadway, R. y Bruce, N. 1984. A General Proposition on the Design of a Neutral Business Tax. Journal of Public Economics 24(2), 231-239.

Boadway, R. y Flatters, F. 1993. The Taxation of Natural Resources: Principles and Policy Issues. World Bank Working Paper 1210.

Boadway, R. y Keen, M. 2003. Theoretical Perspectives on the Taxation of Capital Income and Financial Services (2-44). En Honohan, P. (ed.), Taxation of Financial Intermediation: Theory and Practice for Emerging Economies. New York: Oxford University Press.

Boadway, R. y Marchand, M. 1995. The Use of Public Expenditures for Redistributive Purposes. Oxford Economic Papers 47.

Boarnet, M. y Bogart, W. 1996. Enterprise Zones and Employment: Evidence from New Jersey. Journal of Urban Economics 40(2), 198-215.

Bond, S.R. y Devereux, M.P. 1995. On the Design of a Neutral Business Tax under Uncertainty. Journal of Public Economics 58(1), 57-71. 
Bond, S.R. y Devereux, M.P. 2003. Generalized R-based and S-based Taxes Under Uncertainty. Journal of Public Economics 87(5-6), 1291-1311.

Brewer, M., Saez, E. y Shepard, A. 2010. Means-Testing and Tax Rates on Earnings (90201). En Mirrlees, J. et al. (eds.), Dimensions of Tax Design: The Mirrlees Review. Oxford: Oxford University Press.

Brulhart, M., Gruber, J., Krapf, M. y Schmidheiny, K. 2019. Behavioral Responses to Wealth Taxes: Evidence from Switzerland. CEPR Discussion Paper 14054.

Burman, L. 2010. The Future of Individual Tax Rates: Effects on Economic Growth and Distribution. Statement before the Senate Committee on Finance. Disponible en: https://www.taxpolicycenter.org/publications/future-individual-tax-rateseffects-economic-growth-and-distribution/full [30 de noviembre 2020].

Bye, B., Strom, B. y Avitsland, T. 2012, Welfare Effects of VAT Reforms: A General Equilibrium Analysis. International Tax and Public Finance 19, 368-392.

Chetty, R., Friedman, J. y Saez, E. 2013. Using Differences in Knowledge across Neighborhoods to Uncover the Impacts of the EITC on Earnings. American Economic Review 103(7), 2683-2721.

Cordes, J.J. 1999. Horizontal Equity. En Cordes, J.J., Ebel, R.D. y Gravelle, J.G. (eds.), The Encyclopedia of Taxation and Tax Policy. Washington, DC: The Urban Institute Press.

Couch, J. y Barret, J. 2004. Alabama's Enterprise Zones: Designed to Aid the Needy? Public Finance Review 32(1), 65-81.

Creedy, J. 2011. Reflections on Tax by Design. Fiscal Studies 32(3), 361-373.

Cremer, H. y Gavari, F. 1997. In-Kind Transfers, Self-Selection and Optimal Tax Policy. European Economic Review 41(1), 97-114.

Davies, J.B. y Hoy, M. 2002. Flat Tax Rates and Inequality Measurement. Journal of Public Economics 84(1), 33-46.

Diamond, P.A. 1998. Optimal Income Taxation: An Example with a U-Shaped Pattern of Optimal Marginal Tax Rates. American Economic Review 88(1), 83-95.

Diamond, P. y Saez, E. 2011. The Case for a Progressive Tax: From Basic Research to Policy Recommendations. Journal of Economic Perspectives 25(4), 165-190.

Eissa, N. y Hoynes, H. 2004. Taxes and the Labor Market Participation of Married Couples: The Earned Income Tax Credit. Journal of Public Economics 88(9), 19311958.

Eissa, N. y Hoynes, H. 2006. Behavioral Responses to Taxes: Lessons from the EITC and Labor Supply (73-110). En Poterba, J. (ed.), Tax Policy and the Economy 20. Cambridge, MA: MIT Press.

Eissa, N., Kleven, H. y Kreiner, C. 2008. Evaluation of Four Tax Reforms in the United States: Labor Supply and Welfare Effects for Single Mothers. Journal of Public Economics 92(3-4), 795-816.

Eissa, N. y Hoynes, H. 2011. Redistribution and Tax Expenditures: The Earned Income Tax Credit. National Tax Journal 64(2, Part 2), 689-729.

Francesconi, M., Rainer, H. y Van Der Klaauw, W. 2009. The Effects of In-Work Benefit Reform in Britain on Couples: Theory and Evidence. The Economic Journal 119(535), 66-100. 
Fuest, C., Neumeier, F., Stimmelmayr, M. y Stöhlker, D. 2018. The Economic Effects of a Wealth Tax in Germany. Ifo Institute DICE Report 16(2), 22-26.

Gauthier, S. y Laroque, G. 2009. Separability and Public Finance. Journal of Public Economics 93(11-12), 1168-1174.

Garnaut R. y Ross, A.C. 1983. Taxation of Mineral Rents. Oxford: Oxford University Press.

Gordon, R. 2011. Commentary on Tax by Design: The Mirrlees Review. Fiscal Studies 32(3), 395-414.

Gravelle, J. 1999. The Corporate Income Tax: Economic Issues and Policy Options (1526). En Slemrod, J. (ed.), Tax Policy in the Real World. Cambridge, MA: Cambridge University Press

Gregg, P., Harkness, S. y Smith, S. 2009. Welfare Reform and Lone Parents in the UK. The Economic Journal 119(535), 38-65.

Hansson, A. 2008. The Wealth Tax and Entrepreneurial Activity. The Journal of Entrepreneurship 17(2), 139-156.

Hansson, A. 2010. Is the Wealth Tax Harmful for Economic Growth? World Tax Journal 2(1), 19-34.

Harberger, A. 2008. The Incidence of the Corporation Income Tax Revisited. National Tax Journal 61(2), 303-312.

Heaps, T. y Helliwell, J.F. 1985. The Taxation of Natural Resources (421-472). En Auerbach, A. y Feldstein, M. (eds.), Handbook of Public Economics, Vol. I. Amsterdam: North-Holland.

Hierro, L.A., Gomez-Alvarez, R. y Atienza, P. 2012. The Contribution of US Taxes and Social Transfers to Income Redistribution. Public Finance Review 40(3), 381-400.

Hill, B. y Gurley-Calvez, T. 2019. Earned Income Tax Credits and Infant Health: A Local EITC Investigation. National Tax Journal 72(3), 617-646.

Hoynes, H. y Patel, A. 2018. Effective Policy for Reducing Poverty and Inequality? The Earned Income Tax Credit and the Distribution of Income. Journal of Human Resources 53(4), 859-890.

Jacquet, L., Lehmann, E y Van der Linden, B. 2010. Optimal Redistributive Taxation with both Extensive and Intensive Responses. CESifo Working Paper Series 3308.

Johnson, P. y Myles, G. 2011. The Mirrlees Review. Fiscal Studies 32(3), 331-359.

Kaplow, L. 2006. On the Desirability of Commodity Taxation even when Income Taxation is not Optimal. Journal of Public Economics 90(6-7), 1235-1250.

Kaplow, L. y Shavell, S. 2002. On the Superiority of Corrective Taxes to Quantity Regulation. American Law and Economics Review 4, 1-17.

Keen, M. y Smith, S. 2006. VAT Fraud and Evasion: What Do We Know and What Can Be Done? National Tax Journal 59(4), 861-887.

Keuschnigg, C. 2011. The Design of Capital Income Taxation: Reflections on the Mirrlees Review. Fiscal Studies 32(3), 437-452.

Kleven, H.J., Knudsen, M.B., Kreiner, C.T., Pedersen, S. y Saez, E. 2011. Unwilling or Unable to Cheat? Evidence from a Tax Audit Experiment in Denmark. Econometrica 79(3), 651-692. 
Kopzuck, W. 2001. Redistribution when Avoidance Behavior Is Heterogeneous. Journal of Public Economics 81(1), 51-71.

Laroque, G. 2005. Indirect Taxation is Superfluous under Separability and Taste Homogeneity: A Simple Proof. Economics Letters 87(1), 141-144.

Lund, D. 2002. Rent Taxation When Cost Monitoring Is Imperfect. Resource and Energy Economics 24(3), 211-228.

Lund, D. 2009. Rent Taxation for Nonrenewable Resources. Annual Review of Resource Economics 1(1), 287-307.

Mankiw, G. 2008. Smart Taxes: An Open Invitation to Join the Pigou Club. Eastern Economic Journal 35(1), 14-23.

McLure, C.E., Jr. 1981. The Elusive Incidence of the Corporate Income Tax: The State Case. Public Finance Quarterly 9(4), 395-413.

Mirrlees, J. 1971. An Exploration in the Theory of Optimal Income Taxation. Review of Economic Studies 38(2), 175-208.

Mirrlees, J. 1976. Optimal Tax Theory: A Synthesis. Journal of Public Economics 6(4), 327-358.

Mirrlees, J. 1990. Taxing Uncertain Incomes. Oxford Economic Papers 42, 34-45.

Mirrlees, J., Adam, S., Besley, T., Blundell, R., Bond, S., Chote, R., Gammie, M., Johnson, P., Myles, G. y Poterba, J. (eds.) 2010. Dimensions of Tax Design: The Mirrlees Review. Oxford: Oxford University Press for Institute for Fiscal Studies.

Musgrave, R. 1990. Reaching the Hard-to-Tax (23-46). En Bird, R.M. y Oldman, O. (eds.), Taxation in Developing Countries. Baltimore: John Hopkins University Press.

Nichols, A. y Rothstein, J. 2016. The Earned Income Tax Credit (137-218). En Moffitt, R.A. (ed.), The Economics of Means-Tested Transfer Programs in the United States, Vol. 1. Chicago: University of Chicago Press.

Papke, L. 1991. Interstate Business Tax Differentials and New Firm Location. Evidence from Panel Data. Journal of Public Economics 45(1), 47-68.

Peters, A.H. y Fisher, P.S. 2002. State Enterprise Zone Programs. Have They Worked? Kalamazoo, MI: W.E. Upjohn Institute for Employment Research.

Pichet, E. 2007. The Economic Consequences of the French Wealth Tax. La Revue de Droit Fiscal 14(5), 5.

Portney, P.R., Parry, I.W.H., Gruenspecht, H.K. y Harrington, W. 2003. The Economics of Fuel Economy Standards. Journal of Economic Perspectives 17(4), 203-217.

Prescott, E.C. y Parente, S.L. 2000. Barriers to Riches. Cambridge, London: MIT Press.

Saez, E. 2002. Optimal Income Transfer Programs: Intensive versus Extensive Labor Supply Responses. Quarterly Journal of Economics 117(3), 1039-1073.

Saez, E. 2004. Direct or Indirect Tax Instruments for Redistribution: Short-Run versus Long-Run. Journal of Public Economics 88(3-4), 503-518.

Seade, J. 1977. On the Shape of Optimal Tax Schedules. Journal of Public Economics $7(2), 203-235$.

Seim, D. 2017. Behavioral Responses to Wealth Taxes: Evidence from Sweden. American Economic Journal: Economic Policy 9(4), 395-421.

Servicio de Impuestos Internos 2019. Gasto Tributario 2018-2020. Subdirección de Gestión Estratégica y Estudios Tributarios. Santiago, Chile.

Slemrod, J. 1994. Fixing the Leak in Okun's Bucket Optimal Tax Progressivity when Avoidance Can Be Controlled. Journal of Public Economics 55(1), 41-51. 
Slemrod, J. 2006. The (Compliance) Cost of Taxing Business. Working Paper, University of Michigan. Disponible en: http://webuser.bus.umich.edu/jslemrod/pdf/cost_ of_taxing_business.pdf [30 de noviembre 2020].

Slemrod, J. 2007. Cheating Ourselves: The Economics of Tax Evasion. Journal of Economic Perspectives 21(1), 25-48.

Slemrod, J., Collins, B., Hoopes, J.L., Reck, D. y Sebastiani, M. 2017. Does Credit-Card Information Reporting Improve Small-Business Tax Compliance? Journal of Public Economics 149, 1-19.

Slemrod, J. y Yitzhaki, S. 2002. Tax Avoidance, Evasion, and Administration (14231470). En Auerbach, A. y Feldstein, M. (eds.), Handbook of Public Economics, Vol. 3. Amsterdam: Elsevier.

Sorensen, P. 2007. The Theory of Optimal Taxation: What Is the Policy Relevance? International Tax and Public Finance 14, 383-406.

Sorensen, P. 2009. Dual Income Taxes: A Nordic Tax System. Working Paper, Department of Economics, University of Copenhagen.

Tuomala, M. 1990. Optimal Income Tax and Redistribution. Oxford: Clarendon Press.

West, S. y Williams, R. 2004. Empirical Estimates for Environmental Policy Making in a Second-Best Setting. NBER Working Paper 10330.

Zee, H. 1998. Revenue, Efficiency, and Equity Aspects of Major Taxes in Chile: A Preliminary Assessment. Documento de Trabajo 42, Banco Central de Chile. EP 